\title{
Tensile strength of a surgeon's or a square knot
}

\author{
Tyler M. Muffly, MDa, Jamie Boyce, DO ${ }^{b}$, Sarah L. Kieweg, PhD $^{c}$, and Aaron J. Bonham, \\ MS $^{d}$
}

aSection of Urogynecology and Pelvic Reconstructive Surgery, Department of Obstetrics and Gynecology, Division of Female Pelvic Medicine and Reconstructive Surgery, Cleveland Clinic Foundation, Cleveland, Ohio

bepartment of Obstetrics and Gynecology, University of Missouri - Kansas City, Kansas City, Missouri

'Department of Mechanical Engineering, University of Kansas, Lawrence, Kansas

dOffice for Health Services and Public Health Outcomes Research, University of Missouri Kansas City, Kansas City, Missouri

\begin{abstract}
Objective-To test the integrity of surgeon's knots and flat square knots using four different suture materials.

Study Design-Chromic catgut, polyglactin 910, silk, and polydioxanone sutures were tied in the two types of knot configurations. For all sutures, a 0-gauge United States Pharmacopeia suture was used. Knots were tied by a single investigator (JB). Suture was soaked in $0.9 \%$ sodium chloride for 60 seconds and subsequently transferred to a tensiometer where the tails were cut to 3 mm length. We compared the knots, measuring knot strength using a tensiometer until the sutures broke or untied.
\end{abstract}

Results-A total of 119 knots were tied. We found no difference in mean tension at failure between a surgeon's knot (79.7 Newtons) and a flat square knot (82.9 Newtons). Using a Chisquare test, we did not find a statistically significant difference in the likelihood of knots coming untied between surgeon's knots (29\%) and flat square knots (38\%).

Conclusions-Under laboratory conditions, surgeon's knots and flat square knots did not differ in tension at failure or likelihood of untying.

(C) 2013 Association of Program Directors in Surgery. Published by Elsevier Inc. All rights reserved.

Author responsible for correspondence: Tyler M. Muffly, MD, Fellow, Section of Urogynecology and Pelvic Reconstructive Surgery, Department of Obstetrics and Gynecology, Desk A-81, Obstetrics, Gynecology, and Women Health Institute, Cleveland Clinic, 9500 Euclid Avenue, Cleveland, OH 44195 U.S.A., Office: 216-445-6586, Fax: 216-636-2620, mufflyt@ccf.org.

Publisher's Disclaimer: This is a PDF file of an unedited manuscript that has been accepted for publication. As a service to our customers we are providing this early version of the manuscript. The manuscript will undergo copyediting, typesetting, and review of the resulting proof before it is published in its final citable form. Please note that during the production process errors may be discovered which could affect the content, and all legal disclaimers that apply to the journal pertain.

Accepted as an oral-poster at the $36^{\text {th }}$ Annual Meeting of the Society for Gynecologic, Surgery; Tuscon, AZ; April 14, 2010 


\section{Keywords}

Suture Techniques; Tensile Strength; Suture end length; Polyglactin 910

\section{Introduction}

There is a paucity of data regarding the ideal suture and knot type for surgical procedures. Various knot configurations have been proposed and the most common is the surgeon's knot.[1-2] Flat square knots are the gold standard for surgical procedures because they are more secure when there is a risk of tearing a suture through delicate tissue.[3-4] The square knot is a type of flat reef knot with a single overhand knot with a reversed overhand knot on top.[1-2] A prior study by Tera et al. used suture materials and diameters not commonly used in contemporary pelvic surgery. From a mechanical perspective, theoretically a surgeon's knot should be more secure than a single wrapped throw because of the increased friction from the double wrapped overhand knot. Typically one surgeon's knot is placed, followed by a number of throws based on the surgeon's preference, when opposing mesh, sacrum, and vagina.

The use of a surgeon's knot is a simple modification to the square knot. The surgeon's knot adds an extra twist in the first throw forming a double overhand knot (Figure 1). Surgeons use a surgeon's knot dependent on the suture used, tendency for slippage, and method of tying. Gallup described his preference for tying surgeon's knots when monofilament suture is used.[5] Others prefer to tie a surgeon's knot laparoscopically or robotically as the extra twist will hold its position better for the second throw. The surgeon's knot is widely regarded as the appropriate knot to use during surgical procedures. Multiple surgeons have described rapid and facile methods of performing a surgeon's knot. The idea of placing a surgeon's knot instead of a square knot has been accepted as surgical dogma but has not been studied until this time.

The ideal suture material for surgery should be easy to handle, produce minimal tissue drag, have long lasting tensile strength, and retain strength for sufficient time to give support during fibrous tissue ingrowth into the mesh.[6] Surgeons have attempted to find the suture material that best meets these criteria. The use of a more permanent suture, such as polypropylene, was proposed for sacral colpopexy.[7-8] Permanent suture is not ideal, as chronic pain, vaginal discharge, or erosion can be caused. In the setting of sacral colpopexy, recently published data have shown evidence against the need for permanent suture for graft placement.[9] Jones et al. advocate use of a delayed absorbable monofilament suture for fixation of mesh to the vagina based on the assumption that tissue incorporation into the mesh is the limiting step in determining adequate fixation. When contaminated procedures are combined with clean procedures, increased bacterial load makes the surgeon's choice of suture even more significant.[10]

The purpose of this study is to evaluate the tension at failure of a surgeon's knot with various suture materials, as compared with a square knot tied with those same materials. 


\section{Materials and Methods}

The study was deemed exempt by the University of Missouri Kansas City Institutional Review Board. Four suture materials were chosen for the study: polydioxanone (PDS-II; Ethicon, Inc., Somerville, NJ), polyglactin 910 (Vicryl; Ethicon, Inc), silk (Permahand, Ethicon, Inc.) and chromic surgical gut suture (Ethicon, Inc.). For all sutures, a 0-gauge United States Pharmacopeia size suture was used. We understand that silk is no longer commonly used in some procedures, but it is a historical "gold standard" for suture handling.(11)

For each suture type, knots were tied by each of the following methods: (A) surgeon's knot (defined as a double wrapped first throw followed by a square throws, $2=1=1=1=1$ ) or (B) square knot $(1=1=1=1=1)$ to create a total of 8 material $\times$ knot combinations.(4) All knots were tied by a single investigator. Previous studies have shown that it is necessary to secure monofilament suture with an additional throw compared with multifilament sutures. [8, 12] Therefore polydioxanone was tied with a total of 6 knots: surgeon's knot $(2=1=1=1=1=1)$ or square knot plus five throws $(1=1=1=1=1=1)$. The multifilament sutures were tied with a total of 5 knots: surgeon's knot $(2=1=1=1=1)$ or square knot plus four additional throws $(1=1=1=1=1)$.[3]

The two knot configurations were randomized into sets of eight unique knot combinations. Each randomized set was tied separately to avoid performer bias. All knots were tied wearing surgical gloves on a jig made of two hex-head screws $50 \mathrm{~mm}$ on center. The knots were soaked in $0.9 \%$ sodium chloride solution for 60 seconds to mimic in vivo conditions. The tied suture was then immediately transferred to a Chatillon LTCM-100 tensiometer (Ametek, Largo, FL) where the tails were cut to $3 \mathrm{~mm}$ length (Figure 2).[13] The tensiometer continuously measured load while each suture loop was subjected to tensile forces at a separation rate of $5 \mathrm{~mm} /$ minute until failure occurred. Failure was defined as breakage of the suture or tail slippage greater than $3 \mathrm{~mm}$, and tensile strength or tension at failure was defined as the tensile force $(\mathrm{N})$ measured at failure. To determine the effects of knot type and material on knot strength, we conducted an ANOVA with tests of main effects for both factors and their interaction.

\section{Results}

The proportion of square knots versus surgeon's knots is presented in Table 1. In all cases, knots that began to unravel continued to untie completely. The loads needed to break suture were always greater than those required for suture untying.

\section{Tension at Failure}

A 4x2 ANOVA was conducted to determine whether knot material or knot type (surgeon's knot v. square knot) had any effects on tension at failure. The knot $\times$ material interaction was not statistically significant. The surgeon's knot $(79.7 \mathrm{~N})$ failed at a slightly lower tension than the square knots $(82.9 \mathrm{~N})$, a difference that was not statistically significant. However, there was a significant effect of material on tensile strength $(p=0.03)$. 


\section{Failure type}

Per our power analysis, a total of 119 knots were tied and tested for tension at failure. A Chi-square test was used to determine whether there was a difference in likelihood of coming untied between surgeon's knots (29\%) and square knots (38\%). There was not a statistically significant difference between the two knot types $(\mathrm{p}=0.32)$. The only suture material which untied was polyglactin 910. Among Polyglactin 910 knots 44\% (14 of 32) of surgeon's knots untied and 48\% (27 of 56) of square knots. This difference was also not statistically significant $(\mathrm{p}=0.69)$.

\section{Discussion}

Surgeons continue to seek the ideal suture material and knot configuration. What remains constant is the goal to obtain knot security, despite the lack of standardization between surgeons for knot configurations. Using comparable suture sizes and two different knot constructions, we demonstrate in vitro that a surgeon's knot has no greater tension at failure and is equally as likely to come untied as a square knot.

Suture material possesses certain mechanical properties that are important in knot security. Our results show no difference in tension at failure between surgeon's knot and square configurations. One explanation of why there was no difference between the two configurations is that the extra friction from a second throw of a surgeon's knot may be offset by more acute angulation of the suture. This deforms the suture and creates more gaps between individual throws. We postulate that these gaps decrease friction and thus knot security. Both surgeon's knots and square knots may be appropriate during the same case. This is because the double throw $(2=1)$ of the surgeon's knots provides resistance, but the extra friction limits knot advancement.(14) In contrast, a square knot with two throws (1=1) can be advanced to the mesh surface to secure precise apposition by converting to half hitches that slip.[15] To do this, apply tension to one knot end length perpendicular to the tissue surface and run down the knot to the tissue surface. A square knot is easily and commonly converted to a sliding knot when tying at depth or when tying with coated sutures. Except for abdominal fascia closure, it is rare that a truly "flat" square knot is tied in during a procedure.

To quantitatively evaluate the effect of pathological intra-abdominal pressures on suture response, we modeled the physiological forces on sacral colpopexy sutures using published measurements of intra-abdominal pressures (IAP). Two methods were used to estimate possible forces experienced by sutures in vivo: (1) Laplace's Law and (2) total suspension force on the vagina. Intra-abdominal pressures are reported from the literature for resting and pathological states, as well as for various activities (see Table 2).[16-18] Laplace's Law for thin-walled vessels considers wall tension as in Nout et al. and assumes an abdominal radius of $0.15 \mathrm{~m}$ and an inter-stitch distance of $0.01 \mathrm{~m}$.[16] We estimated forces in each suture ranging from $2 \mathrm{~N}$ (resting normal state) to approximately $75 \mathrm{~N}$ for weight lifting. We also calculated the total suspension force from the vagina to the sacrum using the sacral colpopexy mesh. The suspension analysis calculates a total force from the intra-abdominal pressure acting over the entire outer surface area of the vagina, assumed to be approximately 
$0.006 \mathrm{~m} 2$ based on anatomical measurements.[19] The increased IAP pushes the vagina distally, while the sutures are stretched or pulled in tension. The eight sutures connecting the mesh to the anterior and posterior vaginal walls support the total force caused by IAP. If each of the sutures provides equal support, the force in each suture ranges from $1 \mathrm{~N}$ (resting normal state) to about $38 \mathrm{~N}$ for extreme lifting activities, as shown in Table 2. At the mesh sutured to the anterior longitudinal ligament, the total force is distributed over two sutures, and each suture may be exposed to forces from $4 \mathrm{~N}$ to $150 \mathrm{~N}$.

We have shown that weight lifting can create temporary elevated pressures elevations, and the force on each suture is up to approximately $75 \mathrm{~N}$ at the vagina and up to $150 \mathrm{~N}$ at the sacrum. The range of forces at both sites would render the suture failures documented in our study depending on activity. Additionally, post-operative complications such as ileus and bowel obstruction may further raise abdominal pressure, increasing the likelihood that other activities like valsalva will rupture sutures. Cosson et al. evaluated the force at tissue rupture when a suture was sewn into vaginal tissue samples from patients with prolapse. The vagina, rather than the sutures in the anterior longitudinal ligament, is usually considered the "weakest link" at forces above 75 N. [20] Regardless, it is important to tie a secure knot and understand how to choose appropriate suture and knots. Because of the large range of vaginal tissue rupture forces, we recommend immediately resolving intra-abdominal pressure elevations to improve tissue healing near sutures. We realize that prolapse can recur for many reasons, and one of the most common is tissue quality; we performed this study to evaluate knot failure as an iatrogenic cause of future morbidity.

As with all in vitro research, this study has limitations. Since we had a limited amount of suture, we were unable to use a full length standardized suture at the time it was tied. In the operating room we commonly use a piece of suture more than once and therefore this is an issue of model fidelity. We also purchased the sutures which limited our use of an infinite supply of material. We applied an elongation rate of $5 \mathrm{~mm} /$ minute and monitored tensile forces. Physiological rates of loading during resting, reflex motions (e.g., coughing), voluntary motions (e.g., Valsalva), activities (e.g., exercise), or extreme/explosive activities (e.g., motor vehicle collision) may exert more force over a shorter time period, and at different rates. The difference in the number of throws after the surgeon's knot is not statistically significant based on our unpublished work. We see both first throw knot configurations as acceptable during the same case.

\section{References}

1. Dunn, DL. Wound Closure Manual. Ethicon, Inc.; 2007.

2. Graumont, R.; Hensel, J. Encyclopedia of Knots and Fancy Rope Work. 4th ed. Cornell Maritime Press; 1952.

3. Behm T, Unger JB, Ivy JJ, et al. Flat square knots: are 3 throws enough? Am J Obstet Gynecol. 2007; 197:172, e1-e3. [PubMed: 17689639]

4. van Rijssel EJ, Trimbos JB, Booster MH. Mechanical performance of square knots and sliding knots in surgery: comparative study. Am J Obstet Gynecol. 1990; 162(1):93-97. [PubMed: 2154104]

5. Gallup, DG. Opening and closing the abdomen and wound healing. In: Gershensen, DMCS.; DeCherney, A., editors. Operative Gynecology. 2nd ed. Philadelphia, PA: WB Saunders; 2001. p. 195 
6. Grody, MH. Benign Postreproductive Gynecologic Surgery. 1st ed. New York, NY: McGraw-Hill; 1995.

7. Hogston P. Suture choice in general gynaecological surgery. The Obstetrician and Gynaecologist. 2001; 3:127-131.

8. Dang MC, Thacker JG, Hwang JC, et al. Some biomechanical considerations of polytetrafluoroethylene sutures. Arch Surg. 1990; 125:647-650. [PubMed: 2331223]

9. Jones, KFA.; Abramowitch, D.; Moalli, PA. Evidence Against The Need For Permanent Suture For Graft Placement At The Time Of Abdominal Sacral Colpopexy. Oral Presentation, American Urogynecologic Society 30th Annual Meeting; Hollywood, FL. 2009. 2009.

10. Imparato E, Aspesi G, Rovetta E, et al. Surgical management and prevention of vaginal vault prolapse. Surg Gynecol Obstet. 1992; 175:233-237. [PubMed: 1514157]

11. Ratner, BHA.; Schoen, FJ.; Lemons, JE. Biomaterials Science: an introduction to materials in medicine. 2nd ed. London: Elselvier Academic Press; 2004.

12. Kadirkamanathan SS, Shelton JC, Hepworth CC, et al. A comparison of the strength of knots tied by hand and at laparoscopy. J Am Coll Surg. 1996; 182:46-54. [PubMed: 8542089]

13. Muffly TM, Cook C, Distasio J, et al. Suture End Length as a Function of Knot Integrity. J Surg Educ. 2009; 66:276-280. [PubMed: 20005500]

14. Zimmer CA, Thacker JG, Powell DM, et al. Influence of knot configuration and tying technique on the mechanical performance of sutures. J Emerg Med. 1991; 9:107-113. [PubMed: 2050965]

15. Edlich, RF. Surgical Knot Tying Manual. 3rd ed. Covidien; 2008.

16. Nout E, Lange JF, Salu NE, et al. Creep behavior of commonly used suture materials in abdominal wall surgery. J Surg Res. 2007; 138:51-55. [PubMed: 17137599]

17. Mens J, Hoek van Dijke G, Pool-Goudzwaard A, et al. Possible harmful effects of high intraabdominal pressure on the pelvic girdle. J Biomech. 2006; 39:627-635. [PubMed: 16439232]

18. Gerten KA, Richter HE, Wheeler TLE 2nd, et al. Intraabdominal pressure changes associated with lifting: implications for postoperative activity restrictions. Am J Obstet Gynecol. 2008; 198:306, e1-e5. [PubMed: 18068145]

19. Barnhart KT, Izquierdo A, Pretorius ES, et al. Baseline dimensions of the human vagina. Hum Reprod. 2006; 21(6):1618-1622. [PubMed: 16478763]

20. Cosson M, Lambaudie E, Boukerrou M, et al. A biomechanical study of the strength of vaginal tissues. Results on 16 post-menopausal patients presenting with genital prolapse. Eur J Obstet Gynecol Reprod Biol. 2004; 112:201-205. [PubMed: 14746960] 

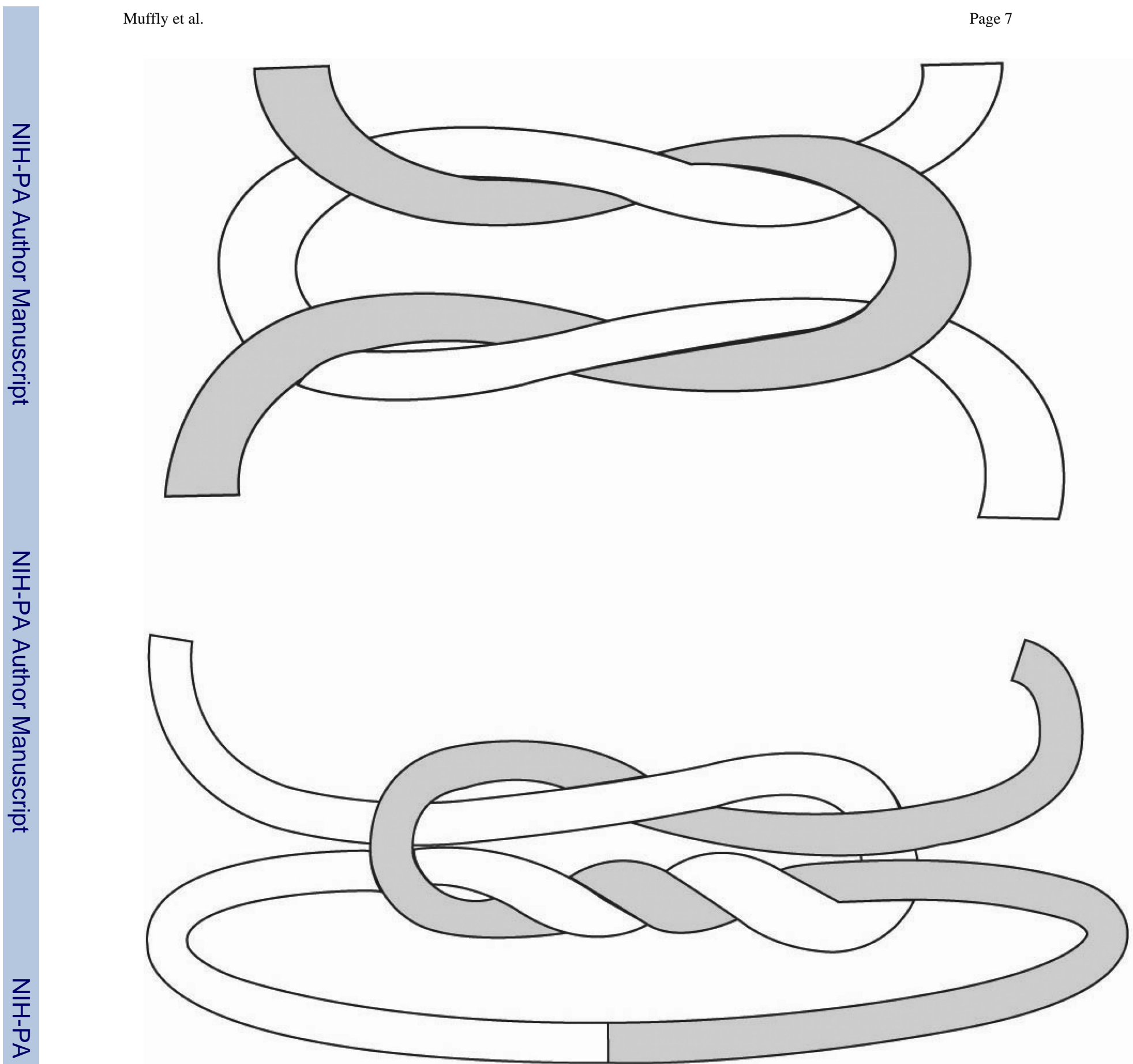

Figure 1.

Configuration of a square and surgeon's knot. (a) Square knot and (b) Surgeon's knot. 


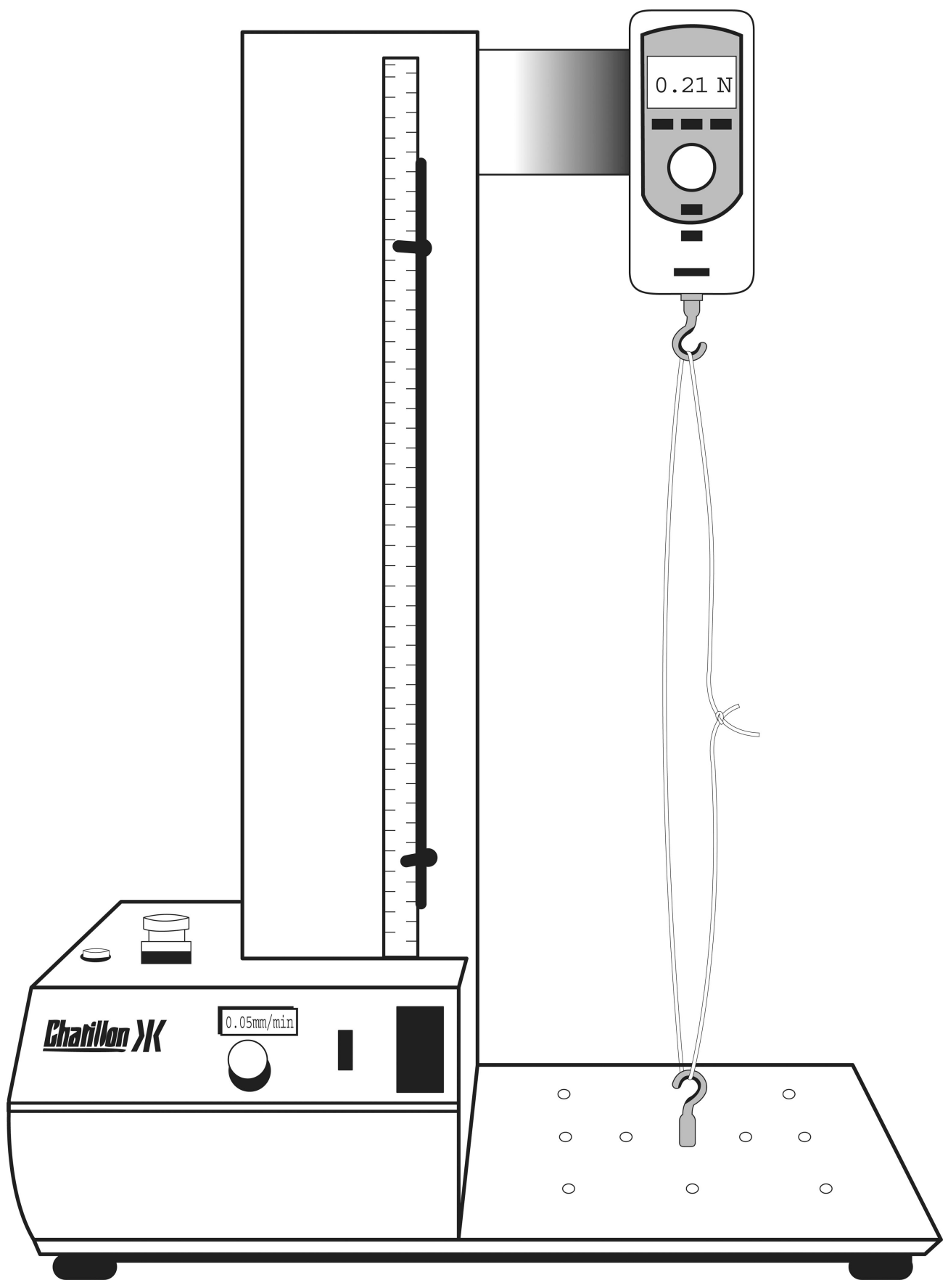

Figure 2.

Tensiometry device elongating suture until failure. 
Table 1

Mean ultimate load until knot failure for each knot configuration and material combination

\begin{tabular}{llrrr}
\hline Knot configuation & Material & N & Mean (Newtons) & SD \\
Surgeon's knot & Polyglactin 910 & 32 & 81.1 & 28.1 \\
& Silk & 6 & 58.7 & 2.7 \\
& Polydioxanone & 5 & 109.1 & 8.1 \\
& Chromic & 5 & 66.9 & 3.9 \\
Square knot & Total & 48 & 79.7 & 26.3 \\
& Polyglactin 910 & 56 & 86.1 & 49.9 \\
& Silk & 5 & 54 & 3.7 \\
& Polydioxanone & 4 & 94.9 & 26.2 \\
& Chromic & 6 & 69.1 & 14.2 \\
& Total & 71 & 82.9 & 45.7 \\
\hline
\end{tabular}




\section{Table 2}

Intra-abdominal pressures for various post-operative activities

\begin{tabular}{llll}
\hline & & $\begin{array}{l}\text { Laplace's Law } \\
\text { (thin-wall } \\
\text { assumption) }\end{array}$ & $\begin{array}{l}\text { Suspension force } \\
\text { (divided over 8 sutures) }\end{array}$ \\
Activity & $\begin{array}{l}\text { IAP } \\
(\mathbf{m m}\end{array}$ & $\begin{array}{l}\text { Force } \\
\text { (Newtons) }\end{array}$ & $\begin{array}{l}\text { Force } \\
\text { (Newtons) }\end{array}$ \\
\cline { 2 - 4 } Resting normal & 10 & 2.0 & 1.00 \\
Squat holding $25 \mathrm{~kg}$ & 59 & 11.8 & 5.88 \\
Laughing & 70 & 14.0 & 6.98 \\
Coughing & 128 & 25.5 & 12.75 \\
Leg lifting & 274 & 54.8 & 27.38 \\
Weight lifting & 375 & 75.0 & 37.50 \\
\hline
\end{tabular}

IAP $=$ Intra-abdominal pressure 